\title{
The Interactive Effects of Dual-Earner Couples' Job Insecurity: Linking Conservation of Resources Theory with Crossover Research
}

Maike E. Debus and Dana Unger

${ }^{1}$ University of Zurich, Switzerland

${ }^{2}$ Swiss Federal Institute of Technology in Zurich (ETHZ), Switzerland

(both authors contributed equally)

Word count (exc. figures/tables): 7889

${ }^{*}$ Correspondence should be addressed to Maike E. Debus, Binzmühlestrasse 14/12, 8050 Zürich, Switzerland (email:

m.debus@psychologie.uzh.ch).

Both authors contributed equally to this study. We would like to thank Martin Kleinmann and Sabine Sonnentag for their comments on an earlier version of this manuscript, and Bess Gutmacher and Justina Veseli for their help with data collection. 
The Interactive Effects of Dual-Earner Couples' Job Insecurity: Linking Conservation of Resources Theory with Crossover Research 


\begin{abstract}
The present study examines job insecurity in the context of dual-earner couples. Linking Conservation of Resources Theory (e.g., Hobfoll, 1989) with crossover research (e.g., Westman, 2001), we proposed that a partner's job insecurity constitutes an additional resource threat. Thus, the partner's job insecurity would exacerbate a person's negative reaction to his or her own job insecurity in terms of attitudinal (i.e., work engagement) and both, health- and withdrawal-related outcomes (i.e., psychological health and turnover intention). Using a time-lagged design and multi-source data from 171 mixed-gender dualearner couples, multilevel path analysis applying the Actor-Partner-Interdependence Model revealed interesting gender differences. The negative relationship between the husband's job insecurity and his work engagement was stronger the higher his wife's job insecurity was. The data further showed a moderated mediation, such that the husband's job insecurity was negatively and indirectly related to both psychological health and turnover intention (via reduced work engagement) if his wife experienced a medium or high level of job insecurity. Our study demonstrates the interactive effects of stressors in dual-earner couples, and highlights the importance of overcoming an overly individualistic perspective when studying job insecurity in particular, and stressors more generally.
\end{abstract}

Keywords: job insecurity, health, work engagement, dual-earner couples, stress

\title{
Practitioner points
}

- Job insecurity has become a highly potent stressor for a large number of employees nowadays. In the context of dual-earner couples, we demonstrate that husbands react more negatively to job insecurity if their wives experience job insecurity too. 
- Dual-earner couples are advised to diversify their occupational background, such that economic downturns in one industry sector are less likely to hit both partners.

- Due to the fact that particularly husbands were affected by the job insecurity of their wives, it is important to tailor psychotherapeutic approaches to this group. Because men are usually more reluctant to approach psychotherapeutic counselling, the rise of job insecurity underscores the need to circumvent chronic mental health problems with adequate interventions.

- Companies are advised to communicate with their employees in a transparent way, such that employees can better cope with organizational plans relating to mergers, acquisitions, and downsizing. 
The Interactive Effects of Dual-Earner Couples' Job Insecurity: Linking Conservation of Resources Theory with Crossover Research

During the past decades, two striking developments have concurrently and fundamentally changed industrialized society. First, repeated recessions, mergers, and acquisitions have contributed to the fact that job insecurity, or a person's concern about his or her future job permanence, has become a significant stressor in today's working life (e.g., Sverke, Hellgren, \& Näswall, 2002). In line with Conservation of Resources (COR) theory (Hobfoll, 1989, 2001), job insecurity denotes the threat to valued resources, which is likely to result in negative outcomes. Second, there has been a substantial change in the roles of men and women in the workforce (Roehling \& Moen, 2003). Today, dual-earner couples, that is, couples in which both partners participate in the labour market, have become the norm (Roehling \& Moen, 2003). As job insecurity is such a widespread phenomenon (cf. Eurofound, 2012; NIOSH, 2013), it can be a concern for both partners in a dual-earner couple.

In the present study, we respond to the aforementioned developments by investigating the effects of job insecurity in the context of dual-earner couples. Linking COR theory (Hobfoll, 1989, 2001) with research on crossover (e.g., Westman, 2001), we predict that job insecurity experienced by a person's partner is an added resource threat to the focal person. As such, the partner's job insecurity will exacerbate the negative relationship between the focal person's own job insecurity and his or her subsequent work engagement. Furthermore, we predict that a process of moderated mediation occurs such that the partner's job insecurity exacerbates the negative relationship between the focal person's job insecurity and his or her work engagement, which, in turn, relates to lower psychological health and higher turnover intention. 
We focus on these outcome variables because work engagement is an affectivemotivational state by which individuals have the ability to work to their full potential. In today's time of fierce competition, it is thus a highly desirable psychological state and a critical antecedent of organizational success (Leiter \& Bakker, 2010). In turn, low psychological health and increased turnover intention belong to the key long-term outcomes of job insecurity which have been argued to be primarily affected via short-term attitudes (such as work engagement, Sverke et al., 2002). These variables further encompass outcomes that are both individually (health) and organizationally-oriented (turnover intention, Sverke et al., 2002). Moreover, situations of prolonged uncertainty make it harder for the individual to use effective and appropriate coping strategies (Lazarus \& Folkman, 1984; Sverke et al., 2002). Thus, individuals are particularly likely to ruminate about this situation which then culminates in poor (psychological) health. In addition, individuals are inclined to withdraw and escape from situations of uncertainty, thus making turnover intention particularly likely. Finally, and from a practical perspective, both low psychological health and turnover intention can undermine a person's optimal functioning at work. Hence, both variables bear high relevance in the present context, because they can result in high costs for both, organizations and society (e.g., Allen, Bryant, \& Vardaman, 2010; WHO, 2003).

By investigating the aforementioned relationships (see Figure 1 for an overview of the theoretical model), our study makes a number of contributions. First, and from a theoretical viewpoint, this study enriches the so-far dominating individual perspective on job insecurity. In examining job insecurity in the context of dual-earner couples, we model processes that result from interactions with others and, thus, take into account the social context (cf. Bronfenbrenner, 1993; Hobfoll, 2001). Moreover, this study expands the literature on crossover, defined as the process whereby experiences and states within one person are transmitted to another person (e.g., Westman, 2001). In that we demonstrate that certain 
experiences of a person's partner (here: job insecurity) affect how the focal person reacts to his or her own stressors, we extend prior research and theory that has predominantly focused on the main-effect transmission of psychological states from one person to another (cf. Bakker, Westman, \& van Emmerik, 2009). In doing so, this study also contributes to stress research more generally because it explores how stressors located in each of the two partners can interact with each other.

\section{[Insert Figure 1 about here]}

Second, we respond to recent calls to more clearly elucidate the processes by which job insecurity affects its outcome variables (e.g., Selenko \& Batinic, 2013). Specifically, we identify reduced work engagement as a critical state that explains why job insecurity relates to reduced psychological health and increased turnover intention. Third, our study's dyadic and lagged design is able to minimize the threat of common method bias (Podsakoff, MacKenzie, \& Podsakoff, 2012). Instead of asking the focal person about how he or she rates the respective partner's job insecurity, we used multi-source data where we asked both partners about their respective levels of job insecurity.

Practically, our study can guide occupational counsellors and employment agencies in dealing with couples experiencing job insecurity. Due to the fact that dual-earner couples can be affected twice by job insecurity, such couples require target group-specific support from these institutions.

\section{Theoretical Background}

In the following, we first explain the construct of job insecurity within the context of COR theory. Linking COR theory with the crossover literature, we then argue that the negative impact of a person's job insecurity on his or her work engagement is amplified by the respective partner's job insecurity which will in turn relate to the focal person's psychological health and turnover intention. 


\section{Job Insecurity in the Context of COR Theory}

COR theory (Hobfoll, 1989, 2001) is one of the most influential theories used to explain human stress and well-being (e.g., Halbesleben, Neveu, Paustian-Underdahl, \& Westman, 2014). The theory states that people "strive to retain, protect, and build resources and that what is threatening to them is the potential or actual loss of these valued resources" (Hobfoll, 1989, p. 516). Strains occur if people experience a threat to one of their resources, an actual resource loss, or a lack of resource gain after a resource investment. Within the context of COR theory, job insecurity denotes the threat to the resource of employment (e.g., König, Debus, Häusler, Lendenmann, \& Kleinmann, 2010), along with the potential loss of several other valued resources, such as financial and social resources (e.g., De Witte, 1999).

Supporting COR theory's tenets, two meta-analyses (Cheng \& Chan, 2008; Sverke et al., 2002) have demonstrated a multitude of detrimental correlates of job insecurity, such as reduced performance, poor health, less commitment to the organization, and higher turnover intention. Hence, Fernandez-Ballesteros (2002) has forecasted job insecurity to be one of the most important issues for applied psychology in the third millennium.

An important distinction among various conceptualizations of job insecurity is the emphasis on cognitive (i.e., the risk of losing one's job) versus affective (i.e., the fear of losing one's job) elements of job insecurity (e.g., Probst, 2008). Recent theoretical models and empirical evidence highlight that affective job insecurity constitutes a reaction to cognitive job insecurity (e.g., Huang, Niu, Lee, \& Ashford, 2012). To separate job insecurity as a stressor from an individual's reaction to this stressor, we follow the majority of past research and focus on cognitive job insecurity in the present study. 


\section{Linking COR Theory and Crossover Research: Interactive Effects of Both Partners' Job Insecurity on Work Engagement}

Researchers have repeatedly highlighted that people do not live in a 'social vacuum,' but are affecting and affected by others around them (Barling, 1990; Westman, 2001). According to Westman's (2001) crossover theory, individuals, particularly partners in intimate relationships, can transmit stressors and strains between each other. This may occur (a) immediately through empathetic reactions and perspective taking (i.e., the focal person empathizes with his or her partner and, thus, shares his or her feelings) or (b) through a mediator (e.g., the partner's stress initiates a negative communication cycle between both partners, such that his or her negative feelings are transmitted to the other person). Moreover, crossover effects may also occur spuriously because both individuals share the same environment (e.g., such as a common stressful life event). This situation can lead to a synchronization of both partners' stress levels. The aforementioned mechanisms are not mutually exclusive and can operate simultaneously (Westman \& Vinokur, 1998).

Conceptualizing these processes as main and/or mediated, most of the research so far has explored how stressors or strains of a person's partner affect the focal person's experiences and well-being and vice versa (e.g., Bakker et al., 2009; Joiner \& Katz, 1999). In the context of job insecurity, for example, Mauno and Kinnunen (2002) have shown that a person's job insecurity is affected by the respective partner's economic stress. Additionally, Westman, Etzion, and Danon (2001) demonstrated the bi-directional crossover of job insecurity within couples (for similar studies in the context of unemployment and downsizing see Song, Foo, Uy, \& Sun, 2011; Westman, Etzion, \& Horovitz, 2004; Westman, Vinokur, Hamilton, \& Roziner, 2004).

In the present study, we extend the above reasoning by linking COR theory with crossover theory. More specifically, we argue that stressors and strains do not only transfer 
from one person to the other as main or mediated effects; instead, how a person reacts to his or her own stressor can be affected by a stressor that resides within the person's partner (i.e., an interactive effect between both partners' stressors). Indeed, Hobfoll (1998) alluded to the process of resource (threat) crossover within couples, noting that "effected individuals exacerbate their distress by exposure to others of equal or worse need" (p. 208). We thus argue that the job insecurity of a person's partner constitutes a further resource threat (because a further income, social networks etc. are at stake), which should in turn exacerbate the focal person's response to his or her own job insecurity (Hobfoll, 1989, 2001).

We focus on work engagement as the outcome variable of the proposed interactive effect of both partners' job insecurities. Engaged individuals are highly vigorous, dedicated, and absorbed in their work (Schaufeli, Bakker, \& Salanova, 2006). These employees, as Leiter and Bakker (2010) noted, "do not hold back" (p. 2), but have the capacity to be energetic, and enthusiastically apply that energy to their work. Thus, work engagement constitutes a critical driver of company success and innovation (e.g., Xanthopoulou, Bakker, Demerouti, \& Schaufeli, 2009). However, if individuals feel that their job is in danger, they are likely to ruminate about this situation, which costs them a considerable amount of energetic and emotional resources (Brosschot, Pieper, \& Thayer, 2005; Sverke et al., 2002). As a consequence, individuals are inclined to emotionally and physically hold back from their work to protect and conserve their remaining resources (Hobfoll, 1989, 2001; for a similar argument see König et al., 2010). Job insecure individuals would, thus, display lower levels of work engagement, because they now withhold their remaining resources in order to deal with their precarious job situation. Indeed, meta-analytic evidence has shown that negative job attitudes and lower involvement in one's work are the strongest and most immediate outcomes of job insecurity (Cheng \& Chan, 2008, for a pimary study on the relationship 
between job insecurity and work engagement see for e.g., Mauno, Kinnunen, \& Ruokolainen, 2007).

Now, imagine the same job insecure person has a partner who is likewise experiencing job insecurity. In this case, the focal person not only has to deal with his or her own job insecurity, but also with the precarious situation of his or her partner. In other words, the focal person will additionally ruminate about the threatening loss of common couple resources (such as the partner's share of the household income and common social contacts); moreover, he or she will also lend an open ear to his or her partner's concerns and/or will need to invest considerable energy into arguments with his or her partner due to the precarious situation (see Westman, 2001). As a consequence, the focal person will have even fewer emotional or energetic resources available that he or she can invest into work. Thus, the focal person will be even less engaged at work in response to his or her own job insecurity (in order to conserve resources) the higher the partner's job insecurity is.

Hypothesis 1: The negative relationship between the focal person's job insecurity and his or her work engagement is moderated by his or her partner's job insecurity: The higher the partner's job insecurity, the stronger is the negative relationship.

\section{The Mediating Role of Work Engagement: Moderated by Partner's Job Insecurity}

Sverke and colleagues (2002) have argued that job attitudes, such as work engagement, constitute more immediate outcomes of job insecurity, which can be separated from outcomes that manifest themselves over a longer period of time. Job insecurity can then affect long-term outcomes through its effects on short-term outcomes (Sverke et al., 2002). In the context of this study, we propose that a person's job insecurity is indirectly related to long-term outcomes via reduced work engagement, which is moderated by the job insecurity of a person's partner. Hence, we propose that a process of a moderated mediation occurs such that the indirect effect of job insecurity on the outcome variables via reduced work 
engagement will be stronger the higher the job insecurity of the person's partner is. In statistical terms, we argue that the $a$ path in a classic meditation model, which links the predictor variable with the mediator (here: the effect of the focal person's job insecurity on work engagement), is moderated (by the respective partner's job insecurity, see Preacher, Rucker, \& Hayes, 2007).

The first long-term outcome in line with Sverke et al.'s (2002) taxonomy that we focus on is psychological health. According to the World Health Organization (WHO), psychological or mental health refers to a psychological state of well-being "in which every individual realizes his or her own potential, can cope with the normal stresses of life, can work productively and fruitfully, and is able to make a contribution to her or his community" (WHO, 2014). The construct constitutes a sub-dimension of an individual's general health as a state of complete physical, mental, and social well-being and not merely the absence of disease or infirmity (Grad, 2002).

There are several reasons to assume that engaged individuals will enjoy better psychological health. First, work engagement is characterized by high levels of energy (Leiter \& Bakker, 2010; Shirom, 2010). Individuals can invest this energy into their work, such that they can realize their full potential and work productively - that is, aspects which are indicative of psychological well-being (for a similar argument see also Halbesleben, 2010). Second, it has been argued that work engagement promotes personal resources such as selfesteem and self-efficacy (e.g., Bakker \& Demerouti, 2008). These resources, in turn, help employees take control of their environment and to succeed in the endeavours that they undertake - an aspect which should likewise culminate in good psychological health. Third, and on a more cognitive level, Broaden and Build Theory (e.g., Fredrickson, 2001) suggests that positive affective states (such as work engagement) broaden individuals' thought-action repertoire. By behaving and thinking more flexibly and in a broader way, individuals enjoy 
wider perspectives of the self and the situation. They can thus make a real contribution to their organization, which likewise fosters mental well-being. ${ }^{1}$

In the context of the present study, individuals experiencing job insecurity would arguably demonstrate worse psychological health because they lack the energetic and personal resources that come with a high level of work engagement. If the focal person is then confronted with a job insecure partner (who needs emotional support and is cared for), he or she will possess even less resources that he or she can invest at work in order to sustain psychological health. Accordingly, the indirect, negative effect of job insecurity on subsequent psychological health via impaired work engagement would be stronger the higher the partner's job insecurity is. Due to the fact that full mediations are very rare in the social sciences (e.g., Cole \& Maxwell, 2003), we assume a partial mediation effect.

Hypothesis 2: The partner's job insecurity moderates the negative indirect effect of the focal person's job insecurity on his or her psychological health via his or her work engagement, such that this indirect effect is stronger (vs. weaker) among employees who have a partner with higher (vs. lower) job insecurity.

The second long-term outcome (see Sverke et al., 2002) which we focus on is turnover intention, defined as a person's conscious and deliberate willingness to leave the organization (e.g., Steel \& Lounsbury, 2009). Turnover intention represents a form of withdrawal from work (see Hom, Mitchell, Lee, \& Griffeth, 2012) and refers to a "set of behaviors that dissatisfied individuals enact to avoid the work situation" (Hulin, 1991, p. 445). The construct of turnover intention lies at the heart of theoretical models which explain the turnover process and has been empirically demonstrated to be the most potent predictor of voluntary turnover (e.g., Hom et al., 2012; Steel \& Lounsbury, 2009).

In terms of the underlying mechanism, virtually all turnover models assume that distal antecedents (such as work conditions or certain personality traits) cause attitudinal 
antecedents, which lead to turnover intentions, and ultimately to voluntary turnover (for an overview see Hom et al., 2012). In the context of our study, this reasoning suggests that employees react to high job insecurity (as an unfavourable work condition) with low work engagement (as an indicator of poor job attitudes), which then culminates in their desire to withdraw from work and to leave their current employer. Since the partner's job insecurity makes the focal person exhibit even less work engagement in response to his or her own job insecurity, the focal person would be even more inclined to withdraw from work. This would allow the focal person to find a new job with a more secure income for both. Thus, the indirect, positive effect of job insecurity on subsequent turnover intention via impaired work engagement would be stronger the higher the partner's job insecurity is. Again, we assume a partial meditation effect.

Hypothesis 3: The partner's job insecurity moderates the positive indirect effect of the focal person's job insecurity on his or her turnover intention via his or her work engagement, such that this indirect effect is stronger (vs. weaker) among employees who have a partner with higher (vs. lower) job insecurity.

\section{Method}

\section{Procedure and Design}

Data were collected in Switzerland and Germany in 2011. To approach potential participants, we advertised our study in newspapers and distributed leaflets. Both partners of a couple had to be employed at least part-time to take part in our study. After individuals had registered for study participation, we sent them individualized links to online-questionnaires (which would later allow us to match the respective partners).

To reduce common method bias, we gathered our predictor and criterion variables at two points in time (Podsakoff et al., 2012). At Time 1, we assessed job insecurity, demographic variables, and the control variables (see below); at Time 2, we assessed work 
engagement, psychological health, and turnover intention. Due to the fact that our predictor variable job insecurity is a rather chronic stressor (e.g., Sverke et al., 2002) and because we do not know when exactly it set in and triggered the stress reaction, we assumed that the three outcomes may not necessarily further deteriorate over time. In other words, the outcome variables might have already reached a plateau at a previous point in time (cf. Sonnentag, Pundt, \& Albrecht, 2014), meaning that they remain stable over time. We, therefore, do not evaluate change in the outcome variables (i.e., we do not control for prior levels of these variables).

\section{Sample}

In total, 516 individuals (i.e., 258 mixed-gender couples) signed up for the study. Of these, 498 individuals fulfilled the requirements to participate in our study, that is, both partners had to indicate that they were currently working. At Time 1, 406 individuals (i.e., 203 couples) completed the first questionnaire. Our final sample consisted of 342 individuals (i.e., 171 couples) who also completed the second questionnaire at Time 2, yielding a response rate of $66 \%$.

The mean age of our final sample was 40.08 years $(S D=9.61)$, and mean tenure was 7.37 years $(S D=7.73)$. Participants had a mean contractual workload of 26.6 hours per week $(S D=7.37)$. In total, $72.22 \%$ of the participants had a permanent contract, and $59.06 \%$ worked in the public (in contrast to the private) sector, thus yielding a relatively heterogeneous sample. Moreover, 282 out of 342 participants (i.e., 82.46\%) had a university or higher professional degree, implying that our sample was relatively well-educated. On average, the partners had been together for 12.44 years $(S D=9.03)$, and had an average number of 1.13 children $(S D=1.08)$. 


\section{Measures}

\section{Study variables.}

Job insecurity. Job insecurity was measured with four items assessing cognitive job insecurity taken from Borg (1992; for the same shortened scale see e.g., Debus, König, \& Kleinmann, 2014). Each item was assessed on a 7-point rating scale ranging from $1=$ not true to $7=$ very true. A sample item is 'My job is secure' (reverse-coded). The scale's internal consistency (i.e., Cronbach's alpha) was .78.

Work engagement. Work engagement was measured with the nine-item Utrecht Work Engagement Scale (Schaufeli et al., 2006), using a seven-point rating scale ranging from $1=$ not true to 7 = very true. A sample item is 'I am enthusiastic about my job'. Cronbach's alpha was .94.

Psychological health. Psychological health was assessed with the 12-item General Health Questionnaire (Goldberg, 1972). Considering the past weeks, participants reported on a four-point scale, for instance, whether they 'felt depressed or unhappy' (reverse-coded; $1=$ not at all; $4=$ much more than usual). Cronbach's alpha was .87.

Turnover intention. Turnover intention was assessed with two items from Staufenbiel and König (2010). A sample item is 'I frequently think of quitting this job'. Participants responded on a 7 -point rating scale $(1=$ not true to $7=$ very true $)$. Cronbach's alpha was .92 .

\section{Control variables.}

At the couple level (Level 2), we controlled for length of relationship and number of children, because both variables might represent protective factors for individual well-being (cf. Hobfoll \& Hobfoll, 1994). ${ }^{2}$ At the individual level (Level 1), we included age as a control variable, because older people have a higher disease susceptibility, which may in turn have an impact on job insecurity, work engagement, psychological health, and turnover intention alike (Heckhausen, Dixon, \& Baltes, 1989). 


\section{Construct Validity}

As stated above, we assessed job insecurity at Time 1 and work engagement, psychological health, and turnover intention at Time 2 . To ensure that the variables measured at Time 2 represent different constructs, we conducted confirmatory factor analyses in Mplus 6 (Muthén \& Muthén, 1998-2010). First, we calculated the average variance extracted (AVE) of each variable, which is the overall variance in the items explained by the latent construct. Second, we analysed the squared correlations of this variable with the other Time 2 variables, which represents the shared variance of both variables (see Fornell \& Larcker, 1981). Discriminant validity is evidenced if a variable's AVE is higher than the squared maximum correlation of this variable with another variable. This was true for all constructs (see Table 1). Thus, work engagement, psychological health, and turnover intention do represent different constructs.

\section{Data analyses}

Due to the nested nature of the data (i.e., individuals were nested within dyads), we tested our hypotheses using the Actor-Partner Interdependence Model (APIM, Kenny, Kashy, \& Cook, 2006; Ledermann, Macho, \& Kenny, 2011) as a specific form of multilevel modelling. Because our sample is comprised of mixed-gender couples, we will use the terms "husbands" and "wives" instead of "focal person" and "partner" from now on. Thus, if the husband constitutes the focal person, his wife constitutes the respective partner - and vice versa. The APIM allows for testing relationships within dyads and distinguishes between actor effects [i.e., intra-individual relationships linking the husband's (wife's) predictor variable with his (her) own dependent variable] and partner effects [i.e., inter-individual relationships linking the husband's (wife's) predictor variable with his wife's (her husband's) dependent variable]. Moreover, the model allows for testing interactions between actor and partner effects (i.e., interaction between both the husband's and the wife's job insecurity in 
this study). In the present case, the job insecurities of both husband and wife constituted the predictor variables, and the time-lagged work engagement, psychological health, and turnover intention ratings constituted the dependent variables. We analysed our data by conducting a multilevel path analysis (using the Mplus software, Muthén \& Muthén, 19982010). Following the recommendations of Kenny et al. (2006), we centred the predictor variables (i.e., job insecurity and the control variables) at the grand mean.

\section{Results}

To find out whether the dyads in the sample, which were theoretically distinguishable by the variable gender, were also empirically distinguishable, we evaluated whether husbands and wives differed with regards to their means, standard deviations, and covariances. In terms of means and standard deviations, we found no differences between husbands and wives. With regards to the covariance matrices, the Box M test revealed that the matrices of men and women differed significantly (Box' $M=29.64, \mathrm{~F}=2.93, d f_{1}=10, d f_{2}=552669.32, p<.001$ ). Thus, we modelled husbands' and wives' variables separately.

We present means, standard deviations, and correlations among our study variables in Table 2.

\section{[Insert Table 2 about here]}

\section{Hypothesis Testing}

To test our hypotheses, we first modelled direct effects of the husband's (wife's) job insecurity on both his (her) own and his wife's (her husband's) work engagement. In doing so, we controlled for the main effects of the predictor and the moderator that need to be taken into account when modelling interaction effects (Cohen, Cohen, West, \& Aiken, 2003). Second, we included a path from the job insecurityhusband $\times$ job insecurity wife $_{\text {interaction term }}$ to the husband's (wife's) work engagement. Third, we added direct effects from the husband's (wife's) job insecurity and work engagement on the husband's (wife's) 
psychological health and turnover intention. Finally, we included the aforementioned Level 1 and Level 2 control variables as predictors of all endogenous variables. As a whole, the model demonstrated a good fit to the data $\left[\chi^{2}(19)=15.58, \mathrm{NNFI}=1.07, \mathrm{CFI}=1.00, \mathrm{RMSEA}\right.$ $=.00] .{ }^{3}$ Figure 2 shows the coefficients of the path analysis for the study variables.

[Insert Figure 2 about here]

To test Hypothesis 1, which stated that the wife's (husband's) job insecurity moderates the relationship between the husband's (wife's) job insecurity and his (her) own work engagement, we inspected the paths going from the job insecurityhusband $\times$ job insecurity wife interaction to the husband's and wife's work engagement. The interaction term was significantly negatively associated with the husband's work engagement (estimate $=$ $-0.07, S E=0.03, p<.05$, see Figure 2), whereas it was unrelated to the wife's work engagement (estimate $=-0.02, S E=0.06, n s)$. Figure 3 depicts the significant interaction, showing that the wife's job insecurity strengthened the negative relationship between the husband's job insecurity and his work engagement. Thus, Hypothesis 1 was supported for husbands, but not for wives.

[Insert Figure 3 about here]

To test Hypothesis 2, which stated that the indirect effect of the husband's (wife's) job insecurity on his (her) own psychological health via work engagement is moderated by the wife's (husband's) job insecurity, we applied multilevel bootstrapping and calculated a 95\% confidence interval (CI) of the indirect effect (cf. Hayes, 2013). We followed recommendations by Preacher et al. (2007) and analysed the proposed indirect effect at three different levels of the moderator variable: when the wife's (husband's) job insecurity was high (i.e., one $S D$ above the average), medium, and low (i.e., one $S D$ below the average). As can be seen in Table 3, the indirect effect of the husband's job insecurity on his psychological health via work engagement was significant when his wife reported a medium or high level 
of job insecurity, but not when she indicated a low level of job insecurity. For the wife, the indirect effects of her job insecurity on her own psychological health via her work engagement were non-significant at all three levels of the husband's job insecurity. Thus, Hypothesis 2 was supported for husbands, but not for wives.

A similar result emerged in the case of Hypothesis 3. The indirect effect of the husband's job insecurity on his turnover intention via impaired work engagement was significant when his wife indicated a high or medium level of job insecurity; this effect was non-significant when the wife's job insecurity was low (see also Table 3). For the wife, the indirect effects of her job insecurity on her own turnover intention via her own work engagement were non-significant at all three levels of her husband's job insecurity. Thus, Hypothesis 3 was supported for husbands, but not for wives.

\section{[Insert Table 3 about here]}

All coefficients of paths linking study variables can be found in Figure 2. To reduce complexity, Figure 2 does not contain the results of the control variables. The Level 1 control variable age was unrelated to the outcomes work engagement, psychological health, and turnover intention. In terms of Level 2 control variables, number of children was positively related to the wife's work engagement (estimate $=0.15, S E=0.07, p<.05$ ) and the husband's turnover intention (estimate $=0.20, S E=0.09, p<.05$ ). Length of relationship was negatively related to the wife's turnover intention (estimate $=-0.06, S E=0.02, p<.05$ ). There were no other significant relationships between the control variables on Level 2 and our outcomes.

\section{Additional Analyses}

To rule out that our results might be due to more simple partner effects, we tested whether there were direct effects of the husband's (wife's) job insecurity on his wife's (her husband's) psychological health and turnover intention. ${ }^{4}$ Modelling these additional paths did 
not improve the model fit $\left[\chi_{2}(15)=11.76, \mathrm{~S}-\mathrm{B} \Delta \chi^{2}=3.87, \Delta d f=4, n s, \mathrm{NNFI}=1.08, \mathrm{CFI}=\right.$ 1.00$, RMSEA $=.00]$. Furthermore, all additionally modelled partner effects were nonsignificant.

In a further additional analysis, we explored the relevance of intra-dyadic job insecurity dispersion, which refers to the absolute difference between both partners' job insecurity ratings (cf. Chan, 1998; Kenny et al., 2006) as a Level 2-variable (see Table 1 for descriptive statistics of this variable). ${ }^{5}$ If job insecurity dispersion is high, this means that husband and wife experience rather different levels of job insecurity, whereas a low level of dispersion means that both partners experience similar levels of job insecurity. We examined this effect, because it appears plausible that if dispersion is high, the partner with the lower job insecurity could act as a role model (Bandura, 1977) for his or her partner in order to secure her or his job, and might be particularly engaged at work to secure resources for the couple. Thus, intradyadic job insecurity dispersion might have beneficial effects for the partners. The results revealed that within-couple job insecurity dispersion was not predictive of husbands' and wives' work engagement (results for husbands: estimate $=0.11, S E=0.07, n s$; results for wives: estimate $=-0.03, S E=0.09, n s)$, above and beyond the direct effects of both partners' job insecurity on this outcome.

\section{Discussion}

By investigating job insecurity in the context of dual-earner couples, the present study demonstrates that the effects of a person's job insecurity are not isolated. Our results showed that job insecure husbands reduced their work engagement even more when their wives were likewise suffering from job insecurity. Furthermore, husbands' job insecurity was related to later health impairments and a higher turnover intention (via reduced work engagement) if their wives had medium or high levels of job insecurity. 
There are several ways in which these findings contribute to the literature. First, and from a theoretical point of view, this study links Hobfoll's COR theory with research on crossover. Although Hobfoll (1998) alludes to the issue of stress and resource (threat) crossover in the context of COR theory (see also Chen, Westman, \& Hobfoll, 2015), this notion has not received much attention in the literature. More specifically, we demonstrated that stressors located in closely-related persons can interact with each other. Thereby, the present study also contributes to crossover research because it demonstrates that a person's stressors and strains may also directly transfer to the well-being of the respective partner. In fact, we also controlled for 'classic' crossover (main) effects in our analyses, that is, the partner effects linking the husband's (wife's) job insecurity with the wife's (husband's) work engagement. The postulated interactive effect between both partners' job insecurity emerged above and beyond the aforementioned (albeit non-significant) partner effect. To conclude, our analyses highlight the importance of looking at interactive effects of both partners' stressors and strains as a further crucial possibility in which crossover may take place.

Moreover, by applying COR theory to the context of intimate dyads, our study draws attention to Hobfoll's $(1998,2001)$ notion that the individual is nested in a number of social systems, such as family, community, and culture. As a consequence, a person's access to resources is not located at the individual level only, but can also take place at these higher levels. Although the study of moderator variables of the job insecurity-outcome link is a very popular approach, only a few studies have actually examined such contextual variables (e.g., Debus, Probst, König, \& Kleinmann, 2012). Thus, by focusing on contextual influences within intimate dyads, our study takes into account the "nested-self" (cf. Hobfoll, 2001) and enriches not only job insecurity research in particular, but also stress research in general.

Finally, the majority of studies have examined direct, or, as mentioned above, interactive effects when linking job insecurity to its outcome variables. To gain more detailed 
knowledge about the underlying mechanisms, several researchers (e.g., Selenko \& Batinic, 2013) have called for a more process perspective approach to the study of job insecurity. The model investigated in this study integrates an interactionist perspective with a process perspective and thus contributes to the aforementioned call.

Three findings merit further consideration. First, although we had not assumed gender differences beforehand, the present findings align with previous research which indicates that job insecurity can be a more severe stressor for men (De Witte, 1999). On the basis of role theory (Eagly, 1987), it has been argued that for husbands, working and earning money is still the core of their role in society, whereas wives have more alternative roles available (household duties, taking care of the children etc.). The greater availability of alternative roles besides work may provide more opportunities for satisfaction and pleasure for wives (Marks, 1977); as a consequence, wives might have accumulated more resources that could act as a protective shield (Ruderman, Ohlott, Panzer, \& King, 2002; Sieber, 1974). In contrast, husbands might be particularly affected by their wives' job insecurity, because this can force them even more in the role of the classical breadwinner who has to solely secure the family income.

Related to this, although the interaction effect between husbands' and wives' job insecurities in the prediction of husbands' work engagement looks relatively small when plotted (see Figure 2), we would like to point to the practical importance and meaning of this finding. The figure reveals that for husbands with highly job insecure wives, the relationship between job insecurity and work engagement is particularly negative. In a practical sense, this pattern may illustrate that for job secure husbands (who have a job insecure wife) the positive aspects of their job are particularly salient - which they then transform into high levels of engagement at work. Once these husbands experience high job insecurity themselves, they might foresee the consequences of this situation for both. They, thus, divert 
as many resources as they can away from work to solve the precarious situation of the couple. This gender-specific pattern points to the complex and difficult situation that men are in when they have a job insecure wife.

Second, husbands did not experience reduced psychological health and higher turnover intention (via reduced work engagement) if their wives had a secure job (= low job insecurity). This finding is indeed interesting, because it suggests that the wife's secure job operates as a back-up resource that the couple can rely on if the husband's job is at stake. Viewed from a different angle, the wife's secure job can be seen as a protective factor for the husband. ${ }^{6}$

Third, with regards to turnover intention, the results point to the fact that there actually appear to be two processes at play. First, the direct effect linking job insecurity to turnover intention shows that both husbands and wives seek to leave their jobs to obtain a more secure job (with a probably more secure income for the couple). Accordingly, job insecurity represents a push factor for employees to find another job. This should particularly hold true in our well-educated sample, which is likely to be characterized by a high level of employability (i.e., the individually perceived likelihood of finding a new job, Berntson, Näswall, \& Sverke, 2010). In contrast, the positive indirect effect of job insecurity on turnover intention (via reduced work engagement) in the case of husbands underlines that the job loses its pull factors. In other words, job insecure husbands do not perceive themselves to be engaged anymore, thus indicating that the job loses its attraction and makes them withdraw from it (cf. Schwarz \& Clore, 1983). Moreover, our findings show that in the context of intimate dyads job insecurity has similar effects on turnover intention compared to when only the individual is considered (cf. Sverke et al., 2002). Hence, our findings disprove the alternate argument that in order to secure at least one income it might be more beneficial that job insecure partners within a couple intend to stay with their jobs. 


\section{Limitations and Directions for Future Research}

Clearly, there are some limitations associated with our study. First, due to the correlational nature of our study, we cannot rule out a reverse causation effect (Ployhart \& Vandenberg, 2010). Thus, it may also be the case that individuals who suffer from poor psychological health or who have high turnover intentions display low work engagement, which then puts their jobs at risk (which may likewise be exacerbated by the respective partner's job insecurity). However, drawing on Sverke et al.'s (2002) theoretically anchored taxonomy on the consequences of job insecurity, along with empirical research demonstrating longitudinal effects of job insecurity on the aforementioned outcomes (e.g., Dekker \& Schaufeli, 1995; Hellgren \& Sverke, 2003), we are relatively confident that causality runs in the proposed direction.

Related to this, future research may also employ instrumental variable techniques in order to rule out endogeneity (i.e., the effect of $x$ on $y$ cannot be interpreted due to issues such as common method variance or third variables). By definition, instrumental variables should ideally highly correlate with the predictor variable, but must not be caused by it (e.g., in the case of job insecurity as the predictor variable a reasonable instrumental variable could be unemployment level at the industry level). An instrumental variable is then inserted in a twostage least square regression and causality is supported when the instrumental variable is (a) strongly related to the predictor variable and is (b) related to the outcome variable only via the predictor variable (for a more elaborate description of this approach see Antonakis, Bendahan, Jacquart, \& Lalive, 2010). To further minimize the threat of same source bias, future research could also obtain more objective measures of the respective outcome variables or use ratings by a different source (e.g., a colleague's rating in the case of work engagement, cf. Ilies, Schwind, Wagner, \& Johnson, 2007, or blood pressure as an objective health measure, e.g., Ilies, Dimotakis, \& De Pater, 2010). 
Second, we employed a two-item measure to assess turnover intention to reduce workload for our participants. Although this scale has been used in several studies (Baillod \& Semmer, 1994; Staufenbiel \& König, 2010) and has also demonstrated good reliability, we agree that "using more items is better" (Eisinga, te Grotenhuis, \& Pelzer, 2013, p. 637) in order to further reduce measurement error.

Our study also offers a number of fruitful avenues for future research. First, future research might benefit from examining the particular resources that job insecure individuals are afraid to lose. Indeed, based upon Jahoda's (1982) latent deprivation theory, Selenko and Batinic (2013) demonstrated that job insecurity is negatively related to the latent benefit 'time structure' and the manifest benefit 'income.' In addition, Hobfoll (2015) identifies other resources (e.g., medical insurance) that job insecure employees might perceive to be at stake. By considering these 'threatened' resources in greater detail, we could gain more insight into the processes through which job insecurity affects its negative outcomes, and which resources individuals can actually access through their partner.

Second, the results of our partial mediation analysis suggest that there are further variables which mediate the negative relationship between job insecurity and the two outcomes psychological health and turnover intention. Due to the notion of 'loss spirals' within COR theory, job insecurity could spur the loss of further resources, which have the potential to impair these outcomes. According to ten Brummelhuis and Bakker (2012), personal resources, for example, can be differentiated into transient energies (e.g., attention and physical energy), more stable constructive personal resources (e.g., health and mental resilience), and highly stable personality resources (e.g., self-esteem and optimism). Thus, one may infer that job insecurity has a negative, albeit temporarily different, impact on all three categories of resources. Investigating these relationships would also benefit the above- 
mentioned call to examine job insecurity from a process perspective, along with gaining more knowledge about the underlying temporal dynamics.

Third, future research might more deeply delve into the exact processes by which the wife's job insecurity affects the husband's job insecurity-outcome relationship. As we mentioned above, theory suggests several mechanisms that might explain how crossover can take place. We did not explicitly test these mechanisms in the present study. However, to get a more comprehensive understanding of the underlying processes, future research is warranted.

As mentioned earlier, job insecurity constitutes a rather chronic stressor, and empirical studies (including ours) usually do not assess the onset of this stressor (for an exception see Mohr, 2000). Accordingly, we were not able to model the exact temporal processes that may occur. In fact, several authors have pointed to the fact that stress reactions may not simply develop in a linear fashion with increasing exposure to the stressor (Frese \& Zapf, 1988; Sonnentag et al., 2014). Initially, job insecure employees are likely to experience an increase in strain; after a while, they might then adjust to the insecure situation, such that their strain levels actually plateau. To examine the exact time course of job insecurity reactions, it is thus crucial that future research takes into account when employees started to experience job insecurity.

Advancing the job insecurity and stress literatures more generally, future research may also explore potential resource gains that can cross over between partners. In the context of job insecurity, the partner's career history (such as experience with employment interviews, knowledge about certain industries) might be helpful in alleviating the negative effects of job insecurity for the focal person. Similarly, a person's partner might also constitute a role model (cf. Bandura, 1977; Neff, Niessen, Sonnentag, \& Unger, 2013) in 
terms of behaviours that prove to be beneficial for one's career, such as effective job search behaviour or career adaptability (see Savickas, 1997).

\section{Practical Implications}

First, employment agencies might be well advised to specifically tailor their counselling to the group of dual-earner couples. For instance, when suggesting a re-location, agencies could aim to improve the job security for both partners within a couple instead of focusing only on one partner. Moreover, employment agencies and occupational counsellors may encourage couples who work in a highly similar industry to diversify their professional background such that detrimental economic developments in one industry are less likely to affect both partners.

Second, and on a more general level, organizational changes such as mergers, acquisitions, and downsizing (due to organizational and/or economic factors within a country), and technological changes are repeatedly mentioned as being drivers of employees' job insecurity perceptions (e.g., Greenhalgh \& Rosenblatt, 2010; Sverke et al., 2002). To counteract these effects, organizations are well advised to communicate with their employees in a transparent and honest way (e.g., Keim, Landis, Pierce, \& Earnest, 2014). In doing so, employees are better able to anticipate organizational changes and to cope with them.

Finally, the finding that particularly husbands were affected by the job insecurity level of their wives underscores how important it is to specifically tailor psychotherapeutic approaches to this group. Because conventional therapeutic interventions have historically been developed for use with women, it comes as no surprise that men are typically more reluctant to seek such help (Shay, 1996). Due to communication and intimate sharing, psychotherapy constitutes "the antithesis of masculinity" (Meth \& Pasick, 1990, p. 152) for most men. Because job insecurity is an ever-increasing phenomenon, there is great demand to circumvent chronic mental health problems with adequate approaches. 


\section{Conclusion}

Taken together, our results highlight the importance of overcoming an overly individualistic perspective when studying the effects of job insecurity in particular, and stressors more generally. Acknowledging that employees do not live in a 'social vacuum' (Barling, 1990), but instead are embedded in a greater social context (e.g., Hobfoll, 1998, 2001) offers us new perspectives on previously ignored stressors and resources that aggravate or buffer the effects of stress. 


\section{Footnotes}

${ }^{1}$ Here it becomes apparent that work engagement and psychological health are interrelated, but distinct constructs. Being part of different processes that take place (i.e., work engagement is part of a motivational process, whereas psychological health is part of an energetic process), work engagement and psychological health also have different scopes. Whereas work engagement refers to an affective-motivational state at work, psychological health is relevant for both work and private life (Hakanen \& Schaufeli, 2012).

${ }^{2}$ We evaluated whether there were mean level differences in our study variables between the two countries of data collection, that is, Switzerland and Germany. There were no significant differences between the two countries [job insecurity: $t(340)=1.82, n s, d=$ 0.40 ; work engagement: $t(340)=-0.90, n s, d=-0.15$; psychological health: $t(340)=1.74, n s$, $d=0.12$; turnover intention: $t(340)=0.42, n s, d=0.13]$. We therefore do not control for country of residence.

${ }^{3}$ We also tested a full-mediation model without direct effects of husbands' and wives' job insecurity on their own psychological health and turnover intention. This model had a significantly worse fit than the partial-mediation model $\left[\chi_{2}(23)=39.65, \mathrm{~S}-\mathrm{B} \Delta \chi^{2}=21.97, \Delta d f\right.$ $=4, p<.001, \mathrm{NNFI}=.73, \mathrm{CFI}=0.89, \mathrm{RMSEA}=.07]$. More importantly however, both models yielded the same results in the hypotheses tests. Detailed results can be obtained from the authors.

${ }^{4}$ We would like to thank the anonymous Reviewer 1 for this suggestion.

${ }^{5}$ To avoid multicollinearity issues (and, thus, nonconvergence of the model), we changed one model specification and omitted the job insecurityhusband $\times$ job insecurity wife $_{\text {f }}$ interaction term when testing the effects of intra-dyadic job insecurity dispersion.

${ }^{6}$ We would like to thank the anonymous Reviewer 2 for directing our attention to the protective role of low job insecurity. 


\section{References}

Allen, D. G., Bryant, P. C., \& Vardaman, J. M. (2010). Retaining talent: Replacing misconceptions with evidence-based strategies. Academy of Management Perspectives, 24, 48-64.

Antonakis, J., Bendahan, S., Jacquart, P., \& Lalive, R. (2010). On making causal claims: A review and recommendations. Leadership Quarterly, 21, 1086-1120. doi: 10.1016/j.leaqua.2010.10.010

Baillod, J., \& Semmer, N. (1994). Fluktuation und Berufsverläufe bei Computerfachleuten [Turnover and career paths of computer specialists]. Zeitschrift für Arbeits- und Organisationspsychologie, 38, 152-163.

Bakker, A. B., \& Demerouti, E. (2008). Towards a model of work engagement. Career Development International, 13, 209-229. doi: 10.1108/13620430810870476

Bakker, A. B., Westman, M., \& van Emmerik, I. J. H. (2009). Advancements in crossover theory. Journal of Managerial Psychology, 24, 206-219. doi:

$10.1108 / 02683940910939304$

Bandura, A. (1977). Social learning theory. Englewood Cliffs, NJ: Prentice Hall.

Barling, J. (1990). Employment, stress and family functioning. Chichester, UK: Wiley.

Berntson, E., Näswall, K., \& Sverke, M. (2010). The moderating role of employability in the association between job insecurity and exit, voice, loyalty and neglect. Economic and Industrial Democracy, 13, 215-230. doi: 10.1177/0143831X09358374

Borg, I. (1992). Überlegungen und Untersuchungen zur Messung der subjektiven Unsicherheit der Arbeitsstelle [Reflections and studies on the measurement of subjective uncertainty of employment]. Zeitschrift für Arbeits- und Organisationspsychologie, 36, 107-116. 
Bronfenbrenner, U. (1993). Ecological models of human development. In M. Gauvain \& M. Cole (Eds.), Readings on the development of children (2nd ed., pp. 37-43). New York, NY: Freeman.

Brosschot, J. F., Pieper, S., \& Thayer, J. F. (2005). Expanding stress theory: Prolonged activation and perseverative cognition. Psychoneuroendocrinology, 30, 1043-1049. doi: 10.1016/j.psyneuen.2005.04.008

Chan, D. (1998). Functional relations among constructs in the same content domain at different levels of analysis: A typology of composition models. Journal of Applied Psychology, 83, 234-246. doi: 10.1037/0021-9010.83.2.234

Chen, S. S., Westman, M., \& Hobfoll, S. E. (2015). The commerce and crossover of resources: Resource conservation in the service of resilience. Stress and Health, 31, 95-105. doi: 10.1002/smi.2574

Cheng, G. H.-L., \& Chan, D. K.-S. (2008). Who suffers more from job insecurity? A metaanalytic review. Applied Psychology: An International Review, 57, 272-303. doi: 10.1111/j.1464-0597.2007.00312.x

Cohen, J., Cohen, P., West, S. G., \& Aiken, L. S. (2003). Applied multiple regression/correlation analysis for the behavioral sciences (3rd ed.). Mahwah, NJ: Lawrence Erlbaum.

Cole, D. A., \& Maxwell, S. E. (2003). Testing mediational models with longitudinal data: Questions and tips in the use of structural equation modeling. Journal of Abnormal Psychology, 112, 558-577. doi: 10.1037/0021-843X.112.4.558

De Witte, H. (1999). Job insecurity and psychological well-being: Review of the literature and exploration of some unresolved issues. European Journal of Work and Organizational Psychology, 8, 155-177. doi: 10.1080/135943299398302 
Debus, M. E., König, C. J., \& Kleinmann, M. (2014). The building blocks of job insecurity: The impact of environmental and person-related variables on job insecurity perceptions. Journal of Occupational and Organizational Psychology, 87, 329 -351. doi: 10.1111/joop.12049

Debus, M. E., Probst, T. M., König, C. J., \& Kleinmann, M. (2012). Catch me if I fall! Enacted uncertainty avoidance and the social safety net as country-level moderators in the job insecurity-job attitudes link. Journal of Applied Psychology, 97, 690-698. doi: $10.1037 / \mathrm{a} 0027832$

Dekker, S. W. A., \& Schaufeli, W. B. (1995). The effects of job insecurity on psychological health and withdrawal: A longitudinal study. Australian Psychologist, 30, 57-63. doi: $10.1080 / 00050069508259607$

Eagly, A. H. (1987). Sex difference in social behavior: A social-role interpretation. Hillsdale, NJ: Erlbaum.

Eisinga, R., te Grotenhuis, M., \& Pelzer, B. (2013). The reliability of a two-item scale: Pearson, Cronbach, or Spearman-Brown? International Journal of Public Health, 58, 637-642. doi: 10.1007/s00038-012-0416-3

Eurofound. (2012). Fifth European Working Conditions Survey. Luxemburg: Publications Office of the European Union.

Fernandez-Ballesteros, R. (2002). Challenges of applied psychology for the third millenium: Introduction to the special issue. Applied Psychology: An International Review, 51, 14. doi: $10.1111 / 1464-0597.0075 z$

Fornell, C., \& Larcker, D. F. (1981). Evaluating structural equation models with unobservable variables and measurement error. Journal of Marketing Research, 18, 39-50. doi: 10.2307/3151312 
Fredrickson, B. L. (2001). The role of positive emotions in positive psychology: The broaden-and-build theory of positive emotions. American Psychologist, 56, 218-226. doi: 10.1037/0003-066x.56.3.218

Frese, M., \& Zapf, D. (1988). Methodological issues in the study of work stress: Objective vs. subjective measurement of work stress and the question of longitudinal studies. In C. L. Cooper \& R. Payne (Eds.), Causes, coping and consequences of stress at work (pp. 375-411). Chichester, England: Wiley.

Goldberg, D. (1972). The detection of psychiatric illness by questionnaire. London, UK: Oxford University Press.

Grad, F. P. (2002). The preamble of the constitution of the World Health Organization. Bulletin of the World Health Organization, 80, 981-984. doi: 10.1590/S004296862002001200014

Greenhalgh, L., \& Rosenblatt, Z. (2010). Evolution of research on job insecurity. International Studies of Management and Organization, 40, 6-19. doi: 10.2753/IMO0020-8825400101

Hakanen, J. J., \& Schaufeli, W. B. (2012). Do burnout and work engagement predict depressive symptoms and life satisfaction? A three-wave seven-year prospective study. Journal of Affective Disorders, 141, 415-424. doi: 10.1016/j.jad.2012.02.043

Halbesleben, J. R. B. (2010). A meta-analysis of work engagement: Relationships with burnout, demands, resources, and consequences. In A. B. Bakker \& M. P. Leiter (Eds.), Work engagement: A handbook of essential theory and research (pp. 102117). New York, NY: Psychology Press.

Halbesleben, J. R. B., Neveu, J. P., Paustian-Underdahl, S. C., \& Westman, M. (2014). Getting to the "COR": Understanding the role of resources in conservation of 
resources theory. Journal of Management, 40, 1334-1364. doi:

$10.1177 / 0149206314527130$

Hayes, A. F. (2013). Introduction to mediation, moderation, and conditional process analysis: A regression-based approach. New York, NY: Guilford Press.

Heckhausen, J., Dixon, R. A., \& Baltes, P. B. (1989). Gains and losses in development throughout adulthood as perceived by different adult age-groups. Developmental Psychology, 25, 109-121. doi: 10.1037//0012-1649.25.1.109

Hellgren, J., \& Sverke, M. (2003). Does job insecurity lead to impaired well-being or vice versa? Estimation of cross-lagged effects using latent variable modelling. Journal of Organizational Behavior, 24, 215-236. doi: 10.1002/job.184

Hobfoll, S. E. (1989). Conservation of resources: A new attempt at conceptualizing stress. American Psychologist, 44, 513-524. doi: 10.1037/0003-066X.44.3.513

Hobfoll, S. E. (1998). Stress, culture and community: The psychology and philosophy of stress. New York, NY: Plenum Press.

Hobfoll, S. E. (2001). The influence of culture, community, and the nested-self in the stress process: Advancing conservation of resources theory. Applied Psychology: An International Review, 80, 337-421. doi: 10.1111/1464-0597.00062

Hobfoll, S. E. (2015). General resource evaluation. Retrieved from http://www.personal.kent.edu/ shobfoll/Files/COR-E.pdf

Hobfoll, S. E., \& Hobfoll, I. H. (1994). Work won't love you back: The dual career couple's survival guide. New York, NY: W. H. Freeman and Company.

Hom, P. W., Mitchell, T. R., Lee, T. W., \& Griffeth, R. W. (2012). Reviewing employee turnover: Focusing on proximal withdrawal states and an expanded criterion. Psychological Bulletin, 138, 831-858. doi: 10.1037/a0027983 
Huang, G. H., Niu, X. Y., Lee, C., \& Ashford, S. J. (2012). Differentiating cognitive and affective job insecurity: Antecedents and outcomes. Journal of Organizational Behavior, 33, 752-769. doi: 10.1002/Job.1815

Hulin, C. L. (1991). Adaptation, persistence, and commitment in organizations. In M. D. Dunnette \& L. M. Hough (Eds.), Handbook of industrial and organizational psychology (2nd ed., Vol. 2, pp. 445-505). Palo Alto, CA: Consulting Psychologist press.

Ilies, R., Dimotakis, N., \& De Pater, I. E. (2010). Psychological and physiological reactions to high workloads: Implications for well-being. Personnel Psychology, 63, 407-436. doi: $10.1111 / \mathrm{j} .1744-6570.2010 .01175 . \mathrm{x}$

Ilies, R., Schwind, K. M., Wagner, D. T., \& Johnson, M. D. (2007). When can employees have a family life? The effects of daily workload and affect on work-family conflict and social behaviors at home. Journal of Applied Psychology, 92, 1368-1379. doi: 10.1037/0021-9010.92.5.1368

Jahoda, M. (1982). Employment and unemployment: A social-psychological analysis. Cambridge, MA: Cambridge University Press.

Joiner, T. E., \& Katz, J. (1999). Contagion of depressive symptoms and mood: Meta-analytic review and explanations from cognitive, behavioral, and interpersonal viewpoints. Clinical Psychology-Science and Practice, 6, 149-164. doi: 10.1093/clipsy/6.2.149

Keim, A. C., Landis, R. S., Pierce, C. A., \& Earnest, D. R. (2014). Why do employees worry about their jobs? A meta-analytic review of predictors of job insecurity. Journal of Occupational Health Psychology, 19, 269-290. doi: 10.1037/A0036743

Kenny, D. A., Kashy, D. A., \& Cook, W. L. (2006). Dyadic data analysis. New York, NY: Guilford Press. 
König, C. J., Debus, M. E., Häusler, S., Lendenmann, N., \& Kleinmann, M. (2010). Examining occupational self-efficacy, work locus of control and communication as moderators of the job insecurity-job performance relationship. Economic and Industrial Democracy, 31, 231-247. doi: 10.1177/0143831X09358629

Lazarus, R. S., \& Folkman, S. (1984). Stress, appraisal, and coping. New York, NY: Springer.

Ledermann, T., Macho, S., \& Kenny, D. A. (2011). Assessing mediation in dyadic data using the Actor-Partner Interdependence Model. Structural Equation Modeling: A Multidisciplinary Journal, 18, 595-612. doi: 10.1080/10705511.2011.607099

Leiter, M. P., \& Bakker, A. B. (2010). Work engagement: Introduction. In A. B. Bakker \& M. P. Leiter (Eds.), Work engagement: A handbook of essential theory and research (pp. 1-9). Hove, England: Psychology Press.

Marks, S. R. (1977). Multiple roles and role strain: Some notes on human energy, time and commitment. American Sociological Review, 42, 921-936. doi: 10.2307/2094577

Mauno, S., \& Kinnunen, U. (2002). Perceived job insecurity among dual-earner couples: Do its antecedents vary according to gender, economic sector and the measure used? Journal of Occupational and Organizational Psychology, 75, 295-314. doi: $10.1348 / 096317902320369721$

Mauno, S., Kinnunen, U., \& Ruokolainen, M. (2007). Job demands and resources as antecedents of work engagement: A longitudinal study. Journal of Vocational Behavior, 70, 149-171. doi: 10.1016/j.jvb.2006.09.002

Meth, R., \& Pasick, R. (1990). Men in therapy: The challenge of change. New York, NY: Guilford.

Mohr, G. B. (2000). The changing significance of different stressors after the announcement of bankruptcy: A longitudinal investigation with special emphasis on job insecurity. 
Journal of Organizational Behavior, 21, 337-359. doi: 10.1002/(SICI)1099-

1379(200005)21:3<337::AID-JOB18>3.0.CO;2-G

Muthén, L. K., \& Muthén, B. O. (1998-2010). Mplus user's guide (6th ed.). Los Angeles, CA: Muthén \& Muthén.

Neff, A., Niessen, C., Sonnentag, S., \& Unger, D. (2013). Expanding crossover research: The crossover of job-related self-efficacy within couples. Human Relations, 66, 803-827. doi: $10.1177 / 0018726712465095$

NIOSH. (2013, October 23). Prevalence of job insecurity among working U.S. adults by services subsector. Retrieved from http://www.cdc.gov/niosh/topics/nhis/service/svcfig9.html

Ployhart, R. E., \& Vandenberg, R. J. (2010). Longitudinal research: The theory, design, and analysis of change. Journal of Management, 36, 94-120. doi:

$10.1177 / 0149206309352110$

Podsakoff, P. M., MacKenzie, S. B., \& Podsakoff, N. P. (2012). Sources of method bias in social science research and recommendations on how to control it. Annual Review of Psychology, 63, 539-569. doi: 10.1146/annurev-psych-120710-100452

Preacher, K. J., Rucker, D. D., \& Hayes, A. F. (2007). Addressing moderated mediation hypotheses: Theory, methods, and prescriptions. Multivariate Behavioral Research, 42, 185-227. doi: 10.1080/00273170701341316

Probst, P. (2008). Job insecurity. In J. Barling \& C. L. Cooper (Eds.), The Sage handbook of organizational behavior: Volume I - Micro (pp. 178-196). London, UK: Sage.

Roehling, P. V., \& Moen, P. (2003). Dual-earner couples. In S. Sweet \& J. Casey (Eds.), Work and family encyclopedia. Chestnut Hill, MA: Sloan Work and Family Research Network. Retrieved from https://workfamily.sas.upenn.edu/wfrnrepo/object/uc0th9x66b90ga7q. 
Ruderman, M. N., Ohlott, P. J., Panzer, K., \& King, S. N. (2002). Benefits of multiple roles for managerial women. Academy of Management Journal, 45, 369-386. doi: $10.2307 / 3069352$

Savickas, M. L. (1997). Career adaptability: An integrative construct for life-span, life-space theory. Career Development Quarterly, 45, 247-259. doi: 10.1002/j.21610045.1997.tb00469.x

Schaufeli, W. B., Bakker, A. B., \& Salanova, M. (2006). The measurement of work engagement with a short questionnaire: A cross-national study. Educational and Psychological Measurement, 66, 701-716. doi: 10.1177/0013164405282471

Schwarz, N., \& Clore, G. L. (1983). Mood, misattribution, and judgments of well-being: Informative and directive functions of affective states. Journal of Personality and Social Psychology, 45, 513-523. doi: 10.1037//0022-3514.45.3.513

Selenko, E., \& Batinic, B. (2013). Job insecurity and the benefits of work. European Journal of Work and Organizational Psychology, 22, 725-736. doi:

$10.1080 / 1359432 x .2012 .703376$

Shay, J. J. (1996). "Okay, I'm here, but I'm not talking!" Psychotherapy with the reluctant male. Psychotherapy, 33, 503-513. doi: 10.1037/0033-3204.33.3.503

Shirom, A. (2010). Feeling energetic at work: On vigor's antecedents. In A. B. Bakker \& M. P. Leiter (Eds.), Work engagement: A handbook of essential theory and research (pp. 69-84). Hove, England: Psychology Press.

Sieber, S. D. (1974). Toward a theory of role accumulation. American Sociological Review, 39, 567-578. doi: 10.2307/2094422

Song, Z. L., Foo, M. D., Uy, M. A., \& Sun, S. H. (2011). Unraveling the daily stress crossover between unemployed individuals and their employed spouses. Journal of Applied Psychology, 96, 151-168. doi: 10.1037/a0021035 
Sonnentag, S., Pundt, A., \& Albrecht, A. (2014). Temporal perpectives on job stress. In A. J. Shipp \& Y. Fried (Eds.), Time and work: How time impacts individuals (Vol. 1, pp. 111-140). Hove, UK: Psychology Press.

Staufenbiel, T., \& König, C. J. (2010). A model for the effects of job insecurity on performance, turnover intention, and absenteeism. Journal of Occupational and Organizational Psychology, 83, 101-117. doi: 10.1348/096317908X401912

Steel, R. P., \& Lounsbury, J. W. (2009). Turnover process models: Review and synthesis of a conceptual literature. Human Resource Management Review, 19, 271-282. doi: 10.1016/j.hrmr.2009.04.002

Sverke, M., Hellgren, J., \& Näswall, K. (2002). No security: A meta-analysis and review of job insecurity and its consequences. Journal of Occupational Health Psychology, 7, 242-264. doi: 10.1037/1076-8998.7.3.242

ten Brummelhuis, L. L., \& Bakker, A. B. (2012). A resource perspective on the work-home interface. American Psychologist, 67, 545-556. doi: 10.1037/a0027974

Westman, M. (2001). Stress and strain crossover. Human Relations, 54, 717-751. doi: $10.1177 / 0018726701546002$

Westman, M., Etzion, D., \& Danon, E. (2001). Job insecurity and crossover of burnout in married couples. Journal of Organizational Behavior, 22, 467-481. doi: 10.1002/job.91

Westman, M., Etzion, D., \& Horovitz, S. (2004). The toll of unemployment does not stop with the unemployed. Human Relations, 57, 823-844. doi:

\section{$10.1177 / 0018726704045767$}

Westman, M., \& Vinokur, A. D. (1998). Unraveling the relationship of distress levels within couples: Common stressors, empathic reactions, or crossover via social interaction? Human Relations, 51, 137-156. doi: 10.1177/001872679805100202 
Westman, M., Vinokur, A. D., Hamilton, V. L., \& Roziner, I. (2004). Crossover of marital dissatisfaction during military downsizing among Russian army officers and their spouses. Journal of Applied Psychology, 89, 769-779. doi: 10.1037/00219010.89.5.769

WHO. (2003). Investing in mental health. Geneva, Switzerland: Author.

WHO. (2014, August). Mental health: A state of well-being. Retrieved from http://www.who.int/features/factfiles/mental_health/en/

Xanthopoulou, D., Bakker, A. B., Demerouti, E., \& Schaufeli, W. B. (2009). Work engagement and financial returns: A diary study on the role of job and personal resources. Journal of Occupational and Organizational Psychology, 82, 183-200. doi: $10.1348 / 096317908 \times 285633$ 
Table 1

Discriminant Validity of the Variables Measured at Time 2

\begin{tabular}{lcccc}
\hline Construct & Average Variance Extracted & $\begin{array}{c}\text { Maximum Squared } \\
\text { Correlation with Other } \\
\text { Construct }\end{array}$ & $\begin{array}{c}\text { Average Variance Extracted } \\
> \\
\text { Maximum Squared } \\
\text { Correlation with Other } \\
\text { Construct? }\end{array}$ & $\begin{array}{c}\text { Indication of Discriminant } \\
\text { Validity? }\end{array}$ \\
\hline Work Engagement & 0.79 & 0.10 & Yes & Yes \\
Psychological Health & 0.42 & 0.18 & Yes & Yes \\
Turnover Intention & 0.84 & 0.18 & Yes & Yes \\
\hline
\end{tabular}

Note. $N=171$ couples (i.e., 342 individuals). 
Table 2

Means, Standard Deviations, and Correlations among the Study Variables

\begin{tabular}{|c|c|c|c|c|c|c|c|c|c|c|c|c|c|c|c|}
\hline Variable & $M$ & $S D$ & 1 & 2 & 3 & 4 & 5 & 6 & 7 & 8 & 9 & 10 & 11 & 12 & 13 \\
\hline 1 Length of Relationship & 12.44 & 9.04 & - & & & & & & & & & & & & \\
\hline 2 Number of Children & 1.13 & 1.09 & .50 & - & & & & & & & & & & & \\
\hline 4 Husband's Age & 4.98 & 9.77 & .64 & .42 & .00 & - & & & & & & & & & \\
\hline 5 Wife's Age & 39.18 & 9.39 & .72 & .52 & -.03 & .90 & - & & & & & & & & \\
\hline $\begin{array}{l}7 \text { Wife's Job Insecurity } \\
\text { (T1) }\end{array}$ & 3.05 & 1.27 & -.15 & -.14 & .44 & -.20 & -.24 & .17 & - & & & & & & \\
\hline $\begin{array}{l}8 \text { Husband's Work } \\
\text { Engagement (T2) }\end{array}$ & 4.94 & 0.99 & .09 & .15 & .09 & .00 & .07 & -.31 & .02 & - & & & & & \\
\hline $\begin{array}{l}9 \text { Wife's Work } \\
\text { Engagement (T2) }\end{array}$ & 5.06 & 0.96 & .07 & .19 & -.03 & .16 & .10 & -.19 & -.03 & .08 & - & & & & \\
\hline $\begin{array}{l}12 \text { Husband's Turnover } \\
\text { Intention (T2) }\end{array}$ & 2.62 & 1.67 & -.17 & -.08 & .07 & -.18 & -.20 & .42 & .06 & -.48 & -.06 & -.21 & -.01 & - & \\
\hline $\begin{array}{l}13 \text { Wife's Turnover } \\
\text { Intention (T2) }\end{array}$ & 2.62 & 1.81 & -.27 & -.19 & .18 & -.16 & -.18 & .20 & .21 & -.09 & -.36 & -.10 & -.17 & .14 & - \\
\hline
\end{tabular}

Note. Correlations $(N=171$ dyads) with $r \geq .15$ are significant at $p<.05$ and with $r \geq .20$ are significant at $p<.01$. 
Table 3

Direct Effects and Conditional Indirect Effects of Job Insecurity on the Outcomes in the Partial-Mediation Model for Husbands and Wives

\begin{tabular}{|c|c|c|c|c|c|c|c|}
\hline \multirow[b]{2}{*}{ Actor } & \multirow[b]{2}{*}{ Outcome } & \multirow[b]{2}{*}{ Effect type } & \multirow[b]{2}{*}{$\begin{array}{c}\text { Level of Partner's } \\
\text { Job Insecurity }\end{array}$} & \multirow[b]{2}{*}{$\begin{array}{c}\text { Effect } \\
\text { estimate }\end{array}$} & \multirow[b]{2}{*}{$S E$} & \multicolumn{2}{|c|}{ Confidence Interval } \\
\hline & & & & & & Lower Limit & Upper Limit \\
\hline \multirow[t]{8}{*}{ Husband } & \multirow{4}{*}{$\begin{array}{l}\text { Psycho- } \\
\text { logical } \\
\text { Health }\end{array}$} & Direct Effect & n.a. & -0.036 & 0.025 & -0.085 & 0.012 \\
\hline & & \multirow{3}{*}{$\begin{array}{l}\text { Indirect Effects via Work } \\
\text { Engagement at Different } \\
\text { Levels of the Wife's Job } \\
\text { Insecurity }\end{array}$} & High & -0.043 & 0.012 & -0.067 & -0.020 \\
\hline & & & Medium & -0.030 & 0.010 & -0.050 & -0.010 \\
\hline & & & Low & -0.017 & 0.012 & -0.041 & 0.007 \\
\hline & \multirow{4}{*}{$\begin{array}{l}\text { Turnover } \\
\text { Intention }\end{array}$} & Direct Effect & n.a. & 0.379 & 0.096 & 0.191 & 0.567 \\
\hline & & Indirect Effects via Work & High & 0.201 & 0.049 & 0.105 & 0.298 \\
\hline & & Engagement at Different & Medium & 0.141 & 0.047 & 0.049 & 0.233 \\
\hline & & $\begin{array}{l}\text { Levels of the Wife's Job } \\
\text { Insecurity }\end{array}$ & Low & 0.080 & 0.058 & -0.034 & 0.195 \\
\hline \multirow[t]{8}{*}{ Wife } & \multirow{4}{*}{$\begin{array}{l}\text { Psycho- } \\
\text { logical } \\
\text { Health }\end{array}$} & Direct Effect & n.a. & -0.005 & 0.024 & -0.051 & 0.042 \\
\hline & & Indirect Effects via Work & High & -0.001 & 0.011 & -0.022 & 0.021 \\
\hline & & Engagement at Different & Medium & 0.002 & 0.006 & -0.010 & 0.013 \\
\hline & & $\begin{array}{l}\text { Levels of the Husband's } \\
\text { Job Insecurity }\end{array}$ & Low & 0.004 & 0.009 & -0.013 & 0.020 \\
\hline & \multirow{4}{*}{$\begin{array}{l}\text { Turnover } \\
\text { Intention }\end{array}$} & Direct Effect & n.a. & 0.266 & 0.100 & 0.071 & 0.461 \\
\hline & & Indirect Effects via Work & High & 0.003 & 0.067 & -0.129 & 0.135 \\
\hline & & Engagement at Different & Medium & -0.009 & 0.037 & -0.083 & 0.064 \\
\hline & & $\begin{array}{l}\text { Levels of the Husband's } \\
\text { Job Insecurity }\end{array}$ & Low & -0.022 & 0.051 & -0.122 & 0.078 \\
\hline
\end{tabular}

Note. $N=171$ couples (i.e., 342 individuals). Bootstrap sample size $=5000$. n.a. $=$ not applicable. 


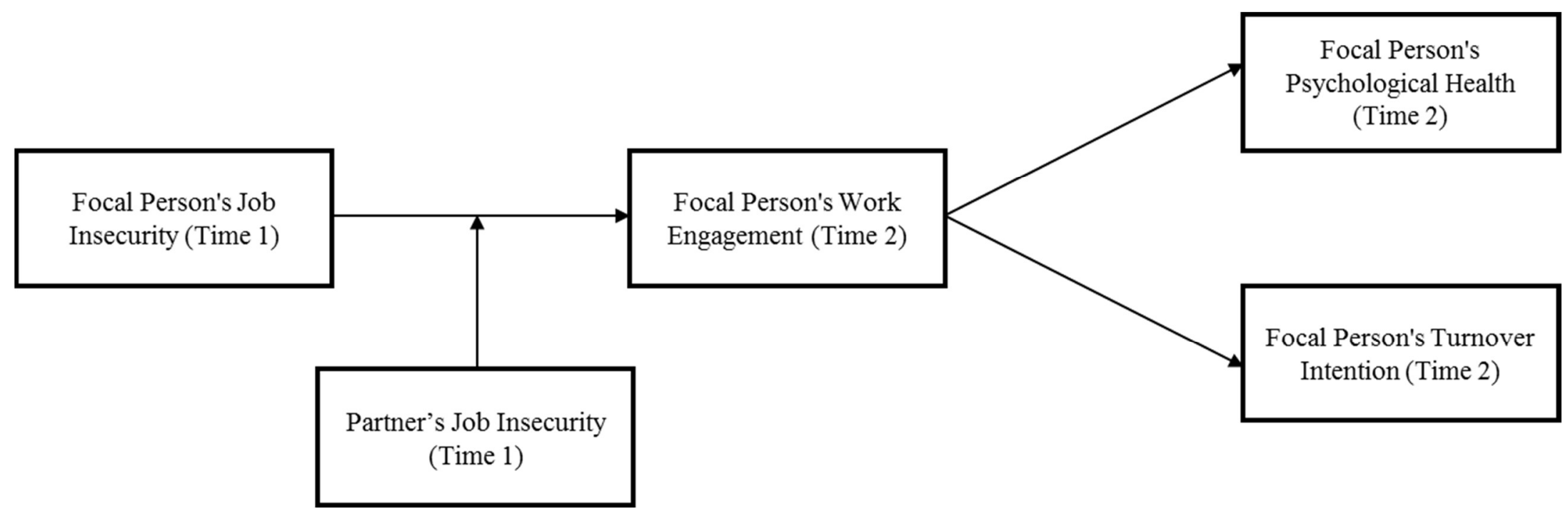

Figure 1. Conceptual Model 


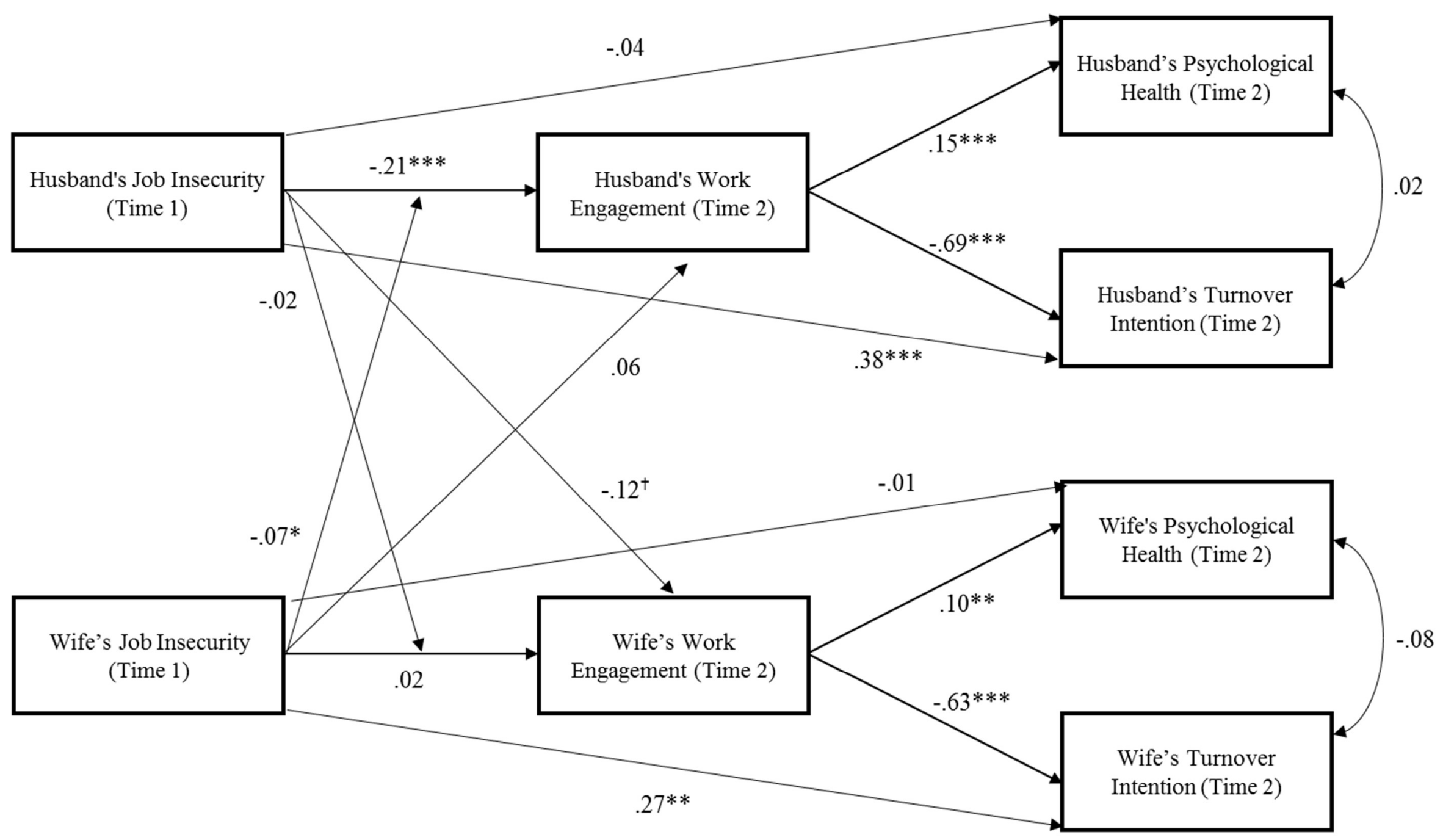

Figure 2. Coefficients yielded by the path analyses. Note: $\dagger<.10 ;{ }^{*} p<.05 ;{ }^{*} p<.01 ;{ }^{* * *} p<.001$. To reduce complexity, we omitted the results for the control variables. 


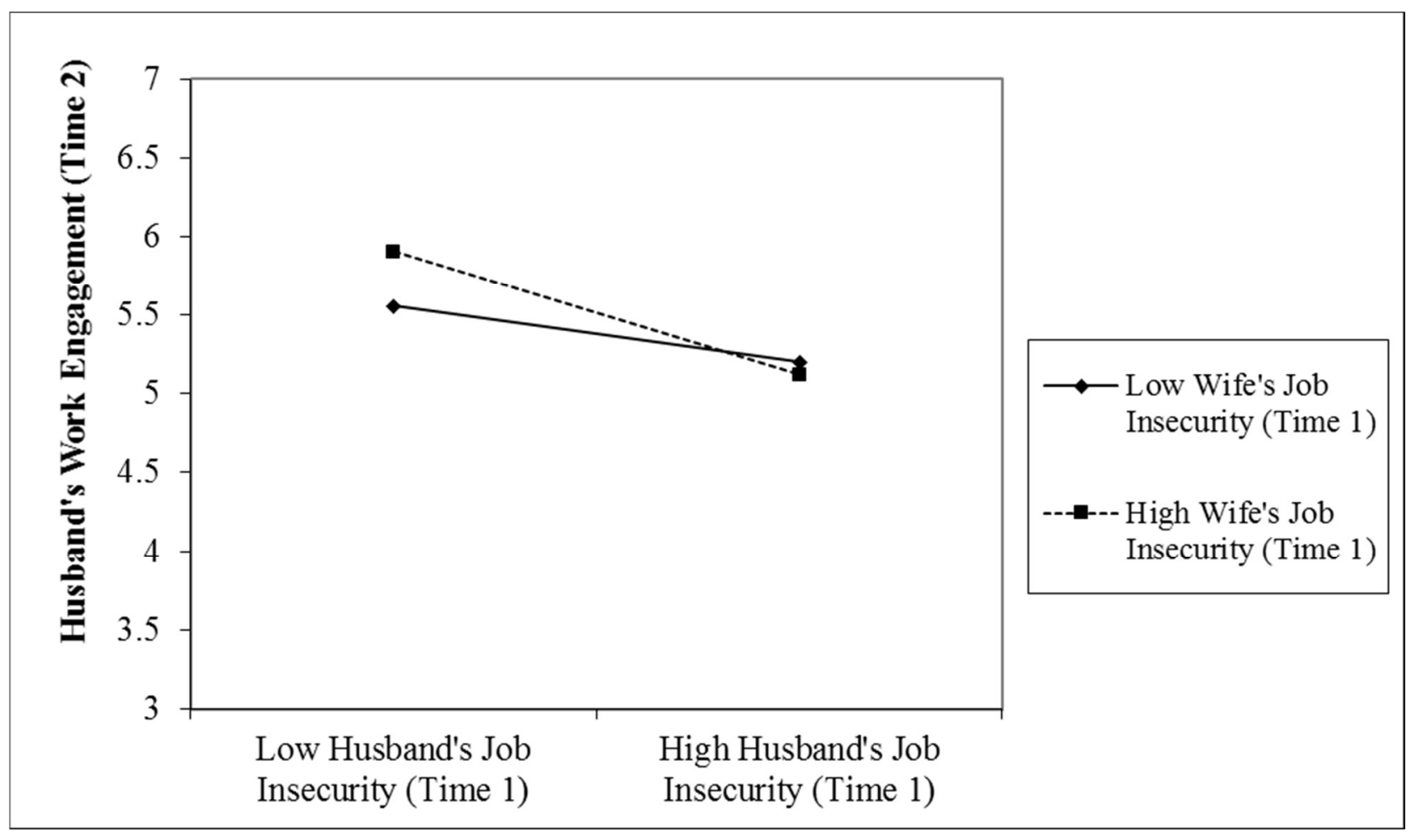

Figure 3. Interaction effect of the husband's and the wife's job insecurity on the husband's work engagement 